\title{
The Challenges and Opportunities for the Development of Regional Economy under the Belt and Road
}

\author{
Fang Yang \\ Weinan Normal University, Weinan, Shaanxi, 714000
}

Keywords: Belt and Road; Regional Economy; Problem Analysis; Development Train of Thought

\begin{abstract}
At the present stage of economic reform in our country, which has been undergoing the reform and opening up for decades, the economy has entered a relatively stable period. However, due to the influence of internal and external factors such as geographical location and development foundation, the unbalanced regional economic development in our country has not yet been completely solved. From a perspective, our country's economic development still lacks lasting power. In 2013, China put forward the "One Belt and One Road Initiative for Development". Its main purpose is to further explore the world market. While injecting new vigor into China's economic development, China will promote the communal development of the world's regional economy. Therefore, the Belt and Road initiative has become the common goal of our country and its neighboring countries The basic strategy of regional economic cooperation is of great significance to strengthening the economic ties among various regions and achieving economic win-win. The article mainly analyzes the opportunities and challenges that the regional economic development faces in the context of the Belt and Road initiative and puts forward the thinking of developing the regional economy.
\end{abstract}

\section{Introduction}

Belt and Road means the Silk Road Economic Belt and the Silk Road on the Sea. Their cooperation focuses on international major thoroughfares and the establishment of an economic and trade industrial park as a platform for cooperation along the Belt and Road so as to promote the economic development of all countries and regions along the line and establish an international Cooperative economic corridor. The development layout along the Belt and Road in our country takes Xinjiang Province and Fujian Province as the economic core areas and the northwest, northeast, Guangxi and Yunnan as the gateway areas and has established eight inland open economy high places and five coastal ports to promote the development of China's Regional economy is balanced and coordinated development.

\section{The Belt and Road brings opportunities for the development of regional economy}

It is doubtless that the construction and development of the strategic objectives of the Belt and Road will provide a good opportunity for the regional economic construction. The development of the regional economy also ushers in entirely new opportunities. The specific performance is as follows:

First of all, the Belt and Road will adjust the differences in regional economic development. The development of regional economy in the eastern and western regions of China is quite different. The cumulative effect of industrial agglomeration in the eastern region is much higher than that in the central and western regions, and its economic base is unmatched in the western region. Although the economic growth rate in the western region in recent years Surpassing the eastern region, but the total economic output of the two regions still lags far behind. One Belt and Road strategy runs through many regions of our country. One of the important development objectives is to achieve the coordinated development of the eastern and western regions of our country and to adjust the differences in regional economy. Second, strengthen regional economic interoperability. The reform and opening up promoted the rapid development of the export-oriented economy in the eastern part 
of our country. However, with the continuous deepening of the reform and opening up, the problem of the lack of motivation for the development of the export-oriented economy in the eastern part of the country has become increasingly prominent, and the economic pull in the central and western regions has not been obvious. The Belt and Road Initiative can enhance economic cooperation among various regions and realize the interconnection and interoperability of the regional economy in the eastern and western regions, creating the conditions for the all-round cooperation in all areas. Third, the development of regional economy can play a role in stratification and optimization. Policy stimulus is an important factor in stimulating economy. However, China's economic development is still in the process of policy digestion, and the adjustment of economic structure and social transformation will also have an impact on the macroeconomic development of our country. The Belt and Road initiative can obviously promote the development of regional economy and stratify and optimize the development path of regional economy according to the different focuses of each region. Finally, the construction of infrastructure drives domestic demand. The western region of our country has $72 \%$ of the land area and a population of only $27 \%$. For a long time, the western region has been limited by infrastructure construction and its economic development has lagged behind the eastern region. In the context of the Belt and Road strategy, the western region has become a transportation hub. In terms of infrastructure construction, it will invest a large amount of funds in the western region to solve the problems of local power, transportation, housing and water conservancy, and greatly improve the infrastructure construction in the western region. Based on the perspective of regional economic development, the first step in implementing the strategy of the Belt and One Road is to solve the problem of infrastructure construction.

\section{The challenges facing the development of regional economy under the Belt and Road strategy}

Although there are many countries along the Belt and Road, covering a large area and covering the total economic output is unprecedented. Although it brings new opportunities for the regional economic development of all countries and regions along the line, due to the level of economic development in various countries and regions, the population Composition and foreign policy. Therefore, the development of regional economy along the line also faces the following challenges: First, whether it can reach a strategic consensus with other countries or regions. Although the strategy for the Belt and the Road has long been proposed, the NDRC, the Ministry of Foreign Affairs and the Ministry of Commerce have issued relevant documents on this great strategy. However, it is undeniable that the strategy of the Belt and the Road is based largely on China's position. However, there is still great uncertainty about their understanding. Countries along the route are likely to think that the Belt and Road initiative is a new opportunity for economic development and may also consider it a Chinese version of the "Marshall Plan." At present, the Belt and One Road strategy has been approved by most countries. However, some economically developed countries such as the United States and Russia are still waiting to see the construction of the Belt and Road needs the recognition of these important economic countries. Otherwise, the construction of the Belt and Road Initiative will be more Great obstacles, it will not mention the integration of regional economic development. Second, the economic performance of the countries along the Belt and Road is seriously imbalanced. Under normal circumstances, the integration and development of regional economy requires that all members be in equal position to complete such as ASEAN members and EU members. However, there is a serious imbalance in the economic development of the countries along the Belt and Road. All the way to achieve there are still many real difficulties. Finally, the development of regional economy has not been based on its actual situation. Since the proposal of the Belt and Road, a strategic plan has been put forward, various domestic regions have made various regional economic development plans around the Belt and Road so as to achieve alignment with the country's strategy and achieve strategic intercommunication in the domestic market. However, many areas have not really analyzed their own situation in depth and only have thought of riding the "East Wind" of the Belt and Road. This situation not only may lead to strategic mistakes in the development of the regional economy but 
will also lead to redundant construction of the economy, waste of resources and even influence The normal development of the regional economy will therefore require the building of a regional economy under the Belt and Road Initiative based on its own actual conditions so as to ensure the steady progress of the construction of the Belt and a road.

\section{The Belt and Road, the background of regional economic development ideas}

Different regions have different economic development and different regions have different positions for economic development. Therefore, regional economic development should be based on regional planning. China's central and western regions have outstanding advantages in terms of human resources. However, the levels of urbanization and industrialization are quite different from those in the eastern region. Both the economic base and the fiscal power are weak, and the industrial structure is not rational and the degree of opening up is not high. Under such circumstances, the regional planning in the western region focuses on ecological protection and gradually undertakes the industrial transfer in other regions, and expands manufacturing based on the development of green industries such as cultural tourism and clean energy. Although the eastern region is economically developed, its environmental protection and energy development are still lacking. Therefore, the regional planning in the eastern region focuses on technological innovation and personnel training and focuses on the high-end service and manufacturing industries.

Since the reform and opening up, all regions and regions have gradually formed their own unique features under the leading role of the market economy. Under the developmental strategy of the Belt and Road initiative, maintaining the economic characteristics of all localities is an important factor affecting the sustainable development of the regional economy. From a short-term point of view, the special economy can directly drive the growth of local GDP and employment rate and bring direct economic benefits to the localities. However, if the special economic sectors in different regions of the Belt and Roadways overlap in the long run or the foreign economy will have an impact on them, all localities should rationally reorient their economic development models. The strategy of regional economic development should embody strong inclusiveness and achieve seamless connection with national planning on the basis of doing well in local economic planning. It is necessary to maintain its own advantages and characteristics, correct its position and actively pursue innovation in the light of its environment Development, they can not refuse to integrate themselves into the new regional economy in order to highlight their own characteristics, nor can they lose their original advantages in order to integrate themselves into the new regional economy.

Economically developed regions usually have sound supporting services. Services are a necessary requirement for the development of the regional economy to a certain degree. The strategy of the Belt and Road is straddling things and faces strong demand for services. Specifically, the construction of regional economic support services can start from the following aspects: First, innovate financial services and provide financial support for the development of regional economy. The financial institutions involved along the Belt and Road include the Silk Fund and the Asian Development Bank. The financial institutions should continue to innovate, learn from the world's advanced economies, set up sub-banks in key cities in accordance with the financial control structure, and adopt the governance structure of the company's operation toward internationalization, marketization, Specialized direction. Build an open financial platform to attract more countries to participate through multilateral agreements. In addition, government departments should also give more policy support to financial innovation services and provide conveniences for financial services in areas such as capital markets, credit, corporate restructuring and information exchange, so as to facilitate economic exchanges between regions and countries. Second, transportation is a priority area for development. Silk Road Economic Belt to strengthen the construction of transport infrastructure such as railways, highways and aviation, especially in the western transport hubs, build modern logistics and warehousing services, deepen the reform of tariffs and ensure the safety of logistic goods. Regional advantages come into play. Finally, strengthen the construction of information service facilities. In the backward areas along the Belt and Road, we will strengthen the building of the communications infrastructure and ensure the smooth flow of information along the 
Belt and Road. However, the "digital short board" existing in some economically backward countries and regions will also bring tremendous business opportunities to the domestic software information service industry.

\section{Conclusion}

Although the strategy of the Belt and Road initiative is directly related to the development of the regional economy at home and abroad and offers opportunities for the integration and development of the regional economy, it should not be blindly optimistic. The problems to be solved in the Belt and Road strategy are still prevalent. The regional economy The integration of development there is still a long way to go. The government departments should constantly improve their own functional management, make scientific adjustments to China's macroeconomic structure and promote the balanced development of the economy in the eastern, central and western regions and strengthen exchanges and cooperation with the countries along the Belt and Road so as to reach a consensus and guarantee Stable progress has been made in the construction of the entire road, making it a new impetus for China to develop its economy and achieve regional economic integration. In short, the realization of the strategic objective of the Belt and Road is a long-term process. In the actual development, we should give full play to the advantages of the all-round cooperation and win-win results in the actual development process, highlight the advantages of cooperation and finally achieve the grand goal of common development.

\section{References}

[1] An Shuwei, "The Belt and Road" on the impact of regional economic development and pattern remodeling [J]. Economic Issues, 2015,10 (4): 88-89.

[2] Li Nuoya. "Belt and Road" economic and financial effects analysis [J]. Financial Expo, 2015,11 (7): 42-43.

[3] Wang Lu. A Study on the Belt and Road Strategy and Regional Cooperation in Three Provinces of Northeast China [J]. Chinese Journal of Knowledge Economy, 2016,15 (1): 152-153.

[4] Xie Shui-yuan. The Strategic Layout of "One Belt and One Road" for Chinese Enterprises going Global: A Perspective Based on the Willingness to Invest in Enterprises [J]. Acta Metallurgica Sinica, 2017 (07): 87-90

[5] Guo Bai-Hong. Analysis of International Competitiveness of Chinese Enterprises under the Strategy of "One Belt and One Road" --A Comparison of State-owned Enterprises and Private Enterprises [J]. China's Value, 2017 (05): 105-106

[6] Zhao Shun. Examining the relationship between the "One Belt and Road" strategy and China's economic development and regional economic cooperation from a macro perspective [J]. International Finance, 2015 (9): 351

[7] Li Xiao, Li Junlong. "Belt and Road" and the Reconstruction of China's Geopolitical and Economic Strategy [J]. World Economy and Politics, 2015 (10): 127-128 